\title{
Analysis of urban vs. rural vasectomy demographics: a multi- institutional, retrospective comparison
}

\author{
G. Luke Machen ${ }^{1}$, Erin T. Bird ${ }^{1}$, Parviz K. Kavoussi ${ }^{2}$ \\ ${ }^{1}$ Division of Urology, Department of Surgery, Scott and White Medical Center/Texas A\&M College of Medicine, Temple, TX, USA; ${ }^{2}$ Austin \\ Fertility \& Reproductive Medicine, Austin, TX, USA \\ Contributions: (I) Conception and design: All authors; (II) Administrative support: ET Bird, PK Kavoussi; (III) Provision of study material or patients: \\ ET Bird, PK Kavoussi; (IV) Collection and assembly of data: GL Machen; (V) Data analysis and interpretation: GL Machen; (VI) Manuscript \\ writing: All authors; (VII) Final approval of manuscript: All authors. \\ Correspondence to: G. Luke Machen, MD. Division of Urology, Scott \& White Medical Center, 2401 S 31st St, Temple TX 76504, USA. \\ Email: glmachen@gmail.com.
}

\begin{abstract}
Background: Each year in the US, approximately 500,000 men choose to undergo a vasectomy for permanent sterilization. Despite being a very common procedure, studies reporting demographic data and characteristics that motivate men to choose a vasectomy are somewhat limited. With this analysis, the primary objective was to determine if a difference existed between the ages and number of children among men choosing to have a vasectomy at urology practices in urban (Austin, TX = City A, population 947,890) and rural (Temple, TX = City B, population 76,277) settings. A secondary objective was to establish if there was a trend in these variables over time.

Methods: After IRB approval was obtained from each institution, a retrospective chart review was undertaken to identify men who had undergone a vasectomy at each facility from 2011-2017. Demographic data was recorded. Statistical analysis was done using student's t-test and linear regression.

Results: The mean age at time of vasectomy in City A was 37.41 years versus 36.18 in City B $(\mathrm{P}<0.001)$. Men in City A underwent vasectomy after a mean of 1.96 children as opposed to a mean of 2.60 children in City B $(\mathrm{P}<0.001)$. There was no statistically significant trend in average age or number of children over time. Conclusions: Men in an urban setting underwent vasectomy at an older age and with fewer children when compared to a rural practice environment. While studies evaluating demographics of men undergoing vasectomy have previously been performed, our results are unique in terms of a direct comparison between different population concentrations.
\end{abstract}

Keywords: Vasectomy; epidemiology; male sterilization; family planning

Submitted Jul 18, 2018. Accepted for publication Aug 01, 2018.

doi: $10.21037 /$ tau.2018.08.02

View this article at: http://dx.doi.org/10.21037/tau.2018.08.02

\section{Introduction}

Each year in the United States, approximately 500,000 men undergo a vasectomy as a means of sterilization, leading to a prevalence of around 6\% (1). Advantages of vasectomy over other forms of permanent or long term birth contraception, include cost-effectiveness, low failure rate, no change in sexual satisfaction, with no risks to the female partner; however, vasectomy remains underutilized (2). Multiple studies have evaluated factors characterizing which men choose to undergo vasectomy, but the majority of this data is from nationally administered surveys. There is a paucity of data comparing characteristics of men selecting vasectomy as their modality for contraception in different population densities and environments.

Studies have evaluated the correlation between age and number of children men have prior to vasectomy $(3,4)$. In this multi-institutional study, the primary objective was to 
Table 1 Summary of demographic data from 2011-2017

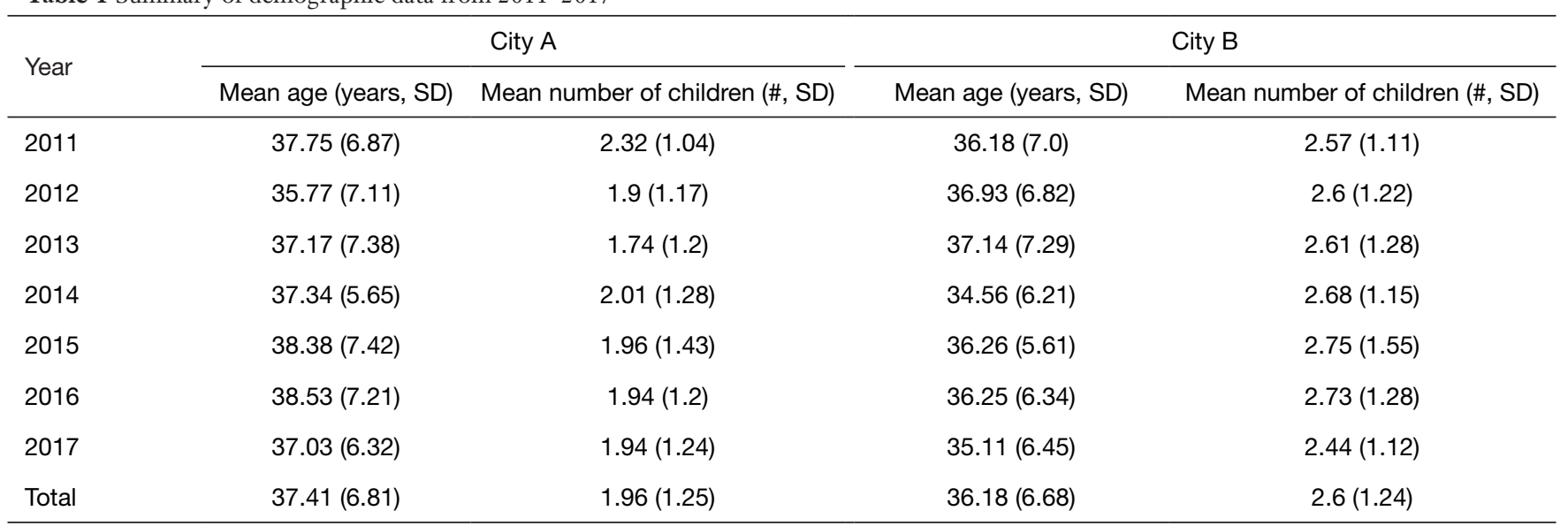

determine if differences existed between age and number of children amongst men who chose to undergo vasectomy between urban (Austin, TX = City A, population 947,980) and rural (Temple, $\mathrm{TX}=$ City B, population 76,277) practice settings. Our secondary objective was to evaluate if there was a difference in the age and number of children of men undergoing vasectomy over time, given the trend towards higher paternal age in the USA over time (5).

\section{Methods}

After IRB approval was obtained from each institution, a retrospective chart review was performed using CPT codes 55250 and 55450 to identify men who had undergone a vasectomy at each facility from 2011-2017. Exclusion criteria included age less than 18 years old and indications aside from desired infertility. Demographic data, including patient age and number of children at the time of vasectomy was recorded. Statistical analyses were performed using linear regression to analyze trends over time and student's t-test to compare means via Graphpad. A P value of less than 0.05 was considered statistically significant.

\section{Results}

Between 2011 and 2017, a total of 1,565 vasectomies were performed-860 in City A and 705 in City B over a 7 year period (Table 1). The cumulative mean age of men in years and number of children at the time of vasectomy were 36.78 (SD 6.73) and 2.26 (SD 1.31), respectively. The mean age in City A was 37.41 years versus 36.18 years in city $\mathrm{B}(\mathrm{P}<0.001$, $95 \%$ CI for difference $0.63-1.85)$. The range of ages for
City A was 20-62 years, while for City B it was 20-64 years. Men in City A underwent vasectomy after having an average of 1.96 (SD 1.25) children, versus a mean of 2.6 (SD 1.24) children in City B $(\mathrm{P}<0.001,95 \%$ CI for difference 0.52 $0.75)$. The ranges of number of children for City A and City B were $0-7$ and $0-10$, respectively.

In regards to the trend over time (Figures 1,2), for City A, there was a slight positive correlation, with the R2 for patient age and number of children prior to vasectomy being both 0.14 , although neither reached statistical significance (P value 0.4 and 0.41 respectively). Similarly, linear regression failed to reach statistical significance for City B, with R2 0.2 and 0.00 for patient age and number of children at time of vasectomy, respectively ( $\mathrm{P}$ values 0.31 and 0.99 ). The $\mathrm{R} 2$ for the cumulative patient population was 0.11 for patient age and 0.16 for number of children, demonstrating a slight positive correlation, although neither reached statistical significance $(\mathrm{P}$ values 0.46 and 0.37 , respectively).

\section{Discussion}

This analysis reveals statistically significant differences $(\mathrm{P}<0.001)$ in both the age of men and the number of children at the time of vasectomy when comparing urban (City A, Austin, TX) to rural (City B, Temple, TX) practice environments, with men in City A having vasectomy at a mean older age and with fewer children. While previous studies have described certain demographic factors, to our knowledge this is the first study detailing a direct comparison of specific parameters between practice settings with differing population densities. 


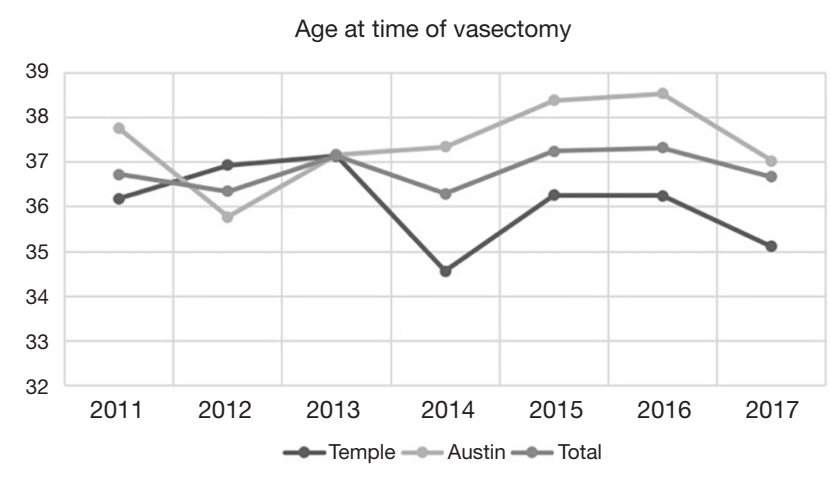

Figure 1 Trend of age at time of vasectomy.

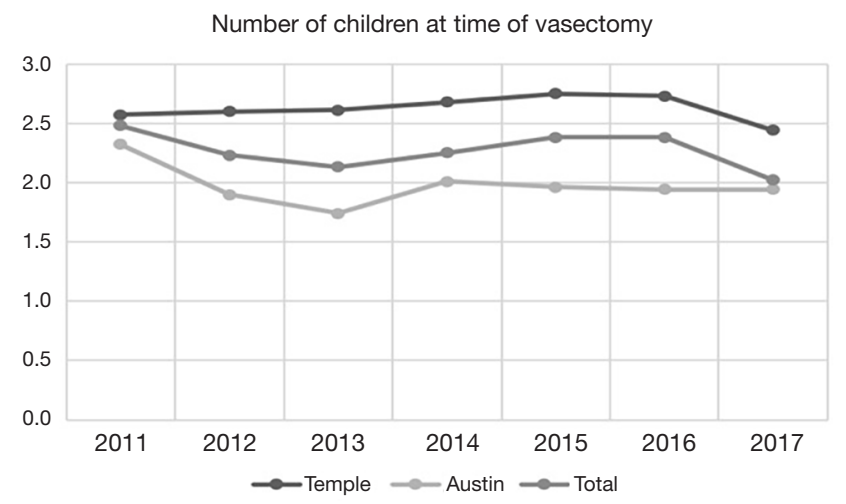

Figure 2 Trend of number of children at time of vasectomy.

The effect of age on the incidence of vasectomy has previously been evaluated. Prior reports have found the mean age at time of vasectomy to be $31-33$ years and have demonstrated that increasing age enhances the likelihood of undergoing a vasectomy $(3,4,6)$. The median age of men at first marriage has increased from 26.3 in 1991 to 28.7 as of 2011 (7), and a recent analysis from Khandwala et al. revealed that the mean paternal age has steadily increased over the last nearly half century in the US, rising from 27.4 in 1972 to 30.9 in 2015 (5). Similar to age, the correlation between number of children and vasectomy status has been described. One report revealed an average number of children of 2.5 at the time of vasectomy (8), while multiple studies have demonstrated increasing odds ratios for vasectomy with increasing number of children, although the effect seems to plateau after having 3 to 4 children $(3,4,9)$.

Our secondary endpoint was to assess whether the mean age and number of children at vasectomy would increase and decrease, respectively, over time with expected population trends. Ultimately, this proved not to be the case, and there was not a statistically significant difference in age at the time of vasectomy over the years in either City $\mathrm{A}$ or $\mathrm{B}$, or for the cumulative data.

It is interesting to consider the differences found amongst men undergoing vasectomy between the two cohorts in our study. One possible explanation is a difference in the levels of education in an urban versus a rural environment. In a report published by the US Department of Health and Human Services in 2012 based on surveys administered to people between the ages of 15 and 44 years, it was found that both men and women with lower levels of education were more likely to have a higher number of children (10). Specifically, men with a bachelor's degree or higher had the lowest mean number of children (1.0), while men with the lowest levels of education were more likely to have 4 or more children. It was also reported that higher levels of education for both men and women were associated with having fewer children before reaching 20 years of age (10). Another study found that fathers with college degrees were typically older compared to those with only a high school diploma at the time of having their first child, 33.3 versus 29.2 years, respectively (6).

Another potential explanation could be the racial breakdown of each community. The effect of race on vasectomy utilization has been previously evaluated, with Caucasians being more likely to utilize vasectomy as a means of permanent contraception $(3,8,11,12)$. However, perhaps more relevant to our results, one study recently demonstrated that, between 2011 and 2015 men of Asian descent had older average paternal age. Specifically, the mean paternal age men of Chinese, Korean, and Asian Indian descent was $34.7,35.0$, and 34.2, compared to mean paternal ages of 31.1 and 30.4 for Caucasians and African Americans, respectively (6). Given the older paternal ages of these ethnicities, it would be reasonable to conclude that the ages at vasectomy of these individuals would correspondingly be later in life. As Austin likely has a more ethnically diverse population relative to Temple, including a rapidly growing Asian population (13), this provides another possible explanation.

The limitations of this study include the fact that each community is represented by a different type of practiceprivate practice for one cohort and a tertiary care center for another-which could have a confounding effect on the results. Additionally, this study is intentionally succinct and focused, but future analysis could expound upon these results include more variables. 


\section{Conclusions}

Men in an urban area chose to have vasectomy at a mean older age and with fewer children than men in a rural setting. While further studies are needed to elucidate the implications of these findings, this study aids in characterizing men who ultimately choose vasectomy and may facilitate strategies increasing utilization of this low risk, cost effective form of permanent sterilization.

\section{Acknowledgements}

None.

\section{Footnote}

Conflicts of Interest: The authors have no conflicts of interest to declare.

Ethical Statement: IRB approval has been obtained from each institution (approval No. 017-406 Scott and White Medical Center; 1147523-1 Fertility Austin).

\section{References}

1. Pile JM, Barone MA. Demographics of vasectomy--USA and international. Urol Clin North Am 2009;36:295-305.

2. Trussell J, Lalla AM, Doan QV, et al. Cost effectiveness of contraceptives in the United States. Contraception 2009;79:5-14. Erratum in: Contraception 2009;80:229-30.

3. Sharma V, Le BV, Sheth KR, et al. Vasectomy demographics and postvasectomy desire for future children: results from a contemporary national survey. Fertil Steril 2013;99:1880-5.

Cite this article as: Machen GL, Bird ET, Kavoussi PK. Analysis of urban $v s$. rural vasectomy demographics: a multiinstitutional, retrospective comparison. Transl Androl Urol 2018;7(6):931-934. doi: 10.21037/tau.2018.08.02
4. Anderson JE, Jamieson DJ, Warner L, et al. Contraceptive sterilization among married adults: national data on who chooses vasectomy and tubal sterilization. Contraception 2012;85:552-7.

5. Khandwala YS, Zhang CA, Lu Y, et al. The age of fathers in the USA is rising: an analysis of 168867480 births from 1972 to 2015. Hum Reprod 2017;32:2110-6.

6. Eisenberg ML, Lipshultz LI. Estimating the number of vasectomies performed annually in the United States: data from the National Survey of Family Growth. J Urol 2010;184:2068-72.

7. Manning WD, Brown SL, Payne KK. Two Decades of Stability and Change in Age at First Union Formation. J Marriage Fam 2014;76:247-60.

8. Barone MA, Johnson CH, Luick MA, et al. Characteristics of men receiving vasectomies in the United States, 19981999. Perspect Sex Reprod Health 2004;36:27-33.

9. Lamberts RW, Guo DP, Li S, et al. The Relationship Between Offspring Sex Ratio and Vasectomy Utilization. Urology 2017;103:112-6.

10. Martinez G, Daniels K, Chandra A. Fertility of men and women aged 15-44 years in the United States: National Survey of Family Growth, 2006-2010. Natl Health Stat Report 2012;(51):1-28.

11. Eisenberg ML, Henderson JT, Amory JK, et al. Racial differences in vasectomy utilization in the United States: data from the national survey of family growth. Urology 2009;74:1020-4.

12. Borrero S, Moore CG, Creinin MD, et al. Low rates of vasectomy among minorities: a result of differential receipt of counseling? Am J Mens Health 2010;4:243-9.

13. Robinson R. Top Ten Demographic Trends in Austin, Texas. Available online: http://austintexas.gov/page/top-tendemographic-trends-austin-texas. Accessed March 17, 2018. 